\title{
Caracterização fenotípica da resistência a antimicrobianos e detecção do gene mecA em Staphylococcus spp. coagulase-negativos isolados de amostras animais e humanas
}

\author{
Phenotypic characterization of antimicrobial resistance and detection of the mecA gene in \\ coagulase-negative Staphylococcus spp. isolates from animal and human samples
}

\author{
Lidiane de Castro Soares ${ }^{I}$ Ingrid Annes Pereira' ${ }^{I}$ Shana de Mattos de Oliveira Coelho ${ }^{\mathrm{I}}$ \\ Cléia Maria Monteiro da CunhaII Débora Fontes Barbosa de Oliveira' \\ Angélica Nogueira Miranda ${ }^{\mathrm{V}}$ Miliane Moreira Soares de Souzav
}

\section{RESUMO}

Os estafilococos coagulase-negativos (ECN) fazem parte da microbiota normal da pele e, apesar de terem sido considerados saprófitas por muito tempo, o seu significado clínico como agente etiológico tem aumentado com o passar dos anos. Neste estudo, foram obtidos 72 isolados de ECN a partir de amostras do conduto auditivo de cães, de mastite bovina e de infecções humanas. Staphylococcus xylosus foi o microrganismo mais isolado, nas amostras animais, e $\mathbf{S}$. cohnii subsp. cohnii em humanos. Os isolados foram avaliados de modo a traçar o perfil fenotípico de sua resistência aos antimicrobianos mais indicados no tratamento de infecções estafilocócicas. Foi detectado um elevado nível de resistência à penicilina e ampicilina. A gentamicina, a vancomicina e a associação ampicilina+sulbactam foram eficientes frente aos isolados testados. A resistência à oxacilina foi avaliada por meio dos testes de difusão em disco modificada, ágar screen, microdiluição em caldo e diluição em ágar para constatar, se à semelhança do que ocorre com os estafilococos coagulasepositivo, esta pode ser mediada pelo gene mecA e apresentada de forma heterogênea. A presença do gene mecA foi determinada pelo método da Reação em Cadeia de Polimerase (PCR), sendo 5,6\% dos isolados mecA positivos.

Palavras-chave: estafilococos coagulase-negativos, oxacilina, gene mecA

\section{ABSTRACT}

Coagulase-negative staphylococci (SCN) make part of the normal microbiota skin and although they have been considered saprophytics for years, nowadays their clinical significance as an etiologic agent has increased. In this study, 72 SCN isolates obtained from external ear canals of dogs, bovine mastitis and human nosocomial infections were evaluated. Staphylococcus xylosus was the most prevalent microorganism in animal samples and $\boldsymbol{S}$. cohnii subsp. cohnii in human samples. SCN isolates were evaluated in order to establish a phenotypical resistance pattern towards the most indicated antibiotics for staphyloccocal infections. A high level of resistance to penicillin and ampicillin was detected. The most efficient antibiotics evaluated were gentamicin, vancomicin and the association between ampicillin and sulbactam. To certify the heterogeneous resistance pattern, oxacillin resistance was phenotypically detected by a modified-disc-diffusion test, agar screen, broth micro-dilution and agar dilution. The presence of the mecA gene was detected in $5.6 \%$ of the SCN isolates by Polimerase Chain Reaction (PCR).

Key words: coagulase-negative staphylococci, methicillin, gene mecA

\section{INTRODUÇÃO}

Os estafilococos coagulase-negativos (ECN) foram, por muito tempo, considerados microrganismos saprófitas e raramente patogênicos. No entanto, atualmente, são reconhecidos como agentes etiológicos de uma série de processos infecciosos, sendo comumente isolados em amostras clínicas humanas e animais (BANNERMAN, 2003). Em animais, a importância dos ECN implicados na mastite bovina tem aumentado nos últimos anos, representando perdas econômicas (GENTILINI et al., 2002). Além disso, estão também associados a infecções do conduto auditivo de cães, embora façam parte da microbiota

'Programa de Pós-graduação em Ciências Veterinárias, Universidade Federal Rural do Rio de Janeiro (UFRRJ), Seropédica, RJ, Brasil.

"Laboratório de Bacteriologia, Instituto Fernandes Figueira (FIOCRUZ), Rio de Janeiro, RJ, Brasil.

IIICurso de Medicina Veterinária, UFRRJ, Seropédica, RJ, Brasil.

${ }^{\mathrm{IV}}$ Curso de Ciências Biológicas, UFRRJ, Seropédica, RJ, Brasil.

vDepartamento de Microbiologia e Imunologia Veterinária, UFRRJ, Campus da UFRRJ, IV, BR 465, Km 7, 23890-000, Seropédica,

RJ, Brasil. E-mail: miliane@ufrrj.br. Autor para correspondência. 
normal (LILENBAUM et al., 2000) e, em humanos, estão envolvidos na infecções nosocomiais (BANNERMAN, 2003).

Nas décadas mais recentes, o aumento no número de infecções por ECN e sua freqüente resistência à meticilina têm se tornado uma dificuldade adicional no controle da infecção por este agente (PALAZZO \& DARINI, 2006). O crescimento da resistência aos antimicrobianos se dá pelo uso inapropriado destes na medicina humana e, também, por práticas usadas na agricultura. As dificuldades no estabelecimento de medidas de controle, no que diz respeito ao uso indiscriminado de antibióticos, ampliam a gama de bactérias resistentes. Além disso, as células bacterianas podem trocar seu material genético, agravando ainda mais este quadro (JOHN et al., 2002).

A resistência à oxacilina em Staphylococcus spp. é heterogênea, conferida principalmente pelo gene mecA, codificador de uma proteína de baixa afinidade a este antimicrobiano, a PBP2a (CAUWELIER et al., 2004). A análise da presença deste gene serve como indicativo e auxilia na escolha da melhor terapia antimicrobiana (FERREIRA et al., 2003).

Considerando-se a ocorrência de cepas de Staphylococcus spp. resistentes à oxacilina na medicina veterinária (GENTILINI et al., 2002) e sabendo-se que ela é o fármaco de escolha no tratamento de infecções estafilocócicas no homem (FERREIRA et al., 2003), a possibilidade de transmissão zoonótica de cepas de Staphylococcus spp. resistentes à oxacilina indica a necessidade de monitorar os perfis de isolamento e suscetibilidade aos antimicrobianos na prática veterinária. Frente a estes dados, o presente trabalho objetivou isolar e identificar Staphylococcus spp. coagulase-negativos a partir de amostras clínicas provenientes de espécie humana e de animais a fim de avaliar o fenótipo de resistência dos isolados aos agentes antimicrobianos, e determinar o seu perfil de suscetibilidade à oxacilina e cefoxitina e detectar a presença do gene mecA.

\section{MATERIAL E METÓDOS}

Para alcançar o objetivo proposto, foram obtidos 16 espécimes clínicos provenientes de amostras coletadas de mastite bovina, 32 isolados do conduto auditivo de cães saudáveis da raça Beagles e 24 isolados clínicos oriundos de amostras humanas provenientes de diversos sítios de infecções hospitalares - perfazendo um total de 72 isolados. Isolamento e identificação: as amostras foram primariamente isoladas em ágar sangue (ágar Columbia acrescido de 5\% de sangue de ovino- Merck), repicadas em ágar manitol vermelho de fenol (MicroMed-Isofar) e o procedimento de identificação foi realizado por meio das provas de Gram, catalase, $\mathrm{KOH}(3 \%)$, produção de coagulase, resistência à bacitracina e novobiocina, redução de nitratos, produção de urease e fermentação de açúcares para identificação das espécies (KONEMAN et al., 2001). Teste de suscetibilidade a antimicrobianos: a suspensão bacteriana utilizada para todos os testes foi preparada por meio da inoculação de colônias isoladas em caldo Müeller-Hinton (M.H.), incubadas por 18 horas a $37^{\circ} \mathrm{C}$ e diluídas na concentração do tubo 0,5 da escala de Mc Farland. A eficácia comparativa da penicilina, oxacilina, vancomicina, ampicilina, gentamicina, cefoxitina e da associação ampicilina e sulbactam foi realizada por meio da difusão em disco simples, utilizando ágar $\mathrm{MH}$ inoculado por 24 horas a $37^{\circ} \mathrm{C}$ (CLSI, 2005). Testes de suscetibilidade à oxacilina: difusão em Disco Modificada - o ágar MH foi suplementado com 4\% de $\mathrm{NaCl}$ e as placas incubadas por 24 horas a 370C. Ágar Screen - a oxacilina foi diluída a uma concentração final de $6 \mu \mathrm{g}$ por $\mathrm{mL}$ de ágar $\mathrm{MH}$, suplementado com $4 \%$ de $\mathrm{NaCl}$ e as placas incubadas por 24 horas a $37^{\circ} \mathrm{C}$. Microdiluição em caldo - a concentração inibitória mínima (CIM) foi determinada por meio de caldo $\mathrm{MH}$ suplementado com $2 \%$ de $\mathrm{NaCl}$, contendo concentrações de $0,25 \mu \mathrm{g} ; 0,5 \mu \mathrm{g} ; 1,0 \mu \mathrm{g} ; 2,0 \mu \mathrm{g} ; 4,0 \mu \mathrm{g}$ e $8,0 \mu \mathrm{g}$ por $\mathrm{mL}$. As suspensões bacterianas foram adicionadas aos caldos e incubadas a $37^{\circ} \mathrm{C}$ por 24 horas (KOHNER et al., 1999). Diluição em Ágar - a oxacilina que foi diluída em ágar M.H. nas concentrações de $0,25 \mu \mathrm{g} \mathrm{mL}^{-1} ; 0,5 \mu \mathrm{g} \mathrm{mL}^{-1} ; 1,0 \mu \mathrm{g} \mathrm{mL}^{-1} ; 2,0 \mu \mathrm{g} \mathrm{mL}^{-1} ; 4,0 \mu \mathrm{g}$ $\mathrm{mL}^{-1}$ até $8,0 \mu \mathrm{g} \mathrm{mL}^{-1}$. O resultado foi obtido pela avaliação do crescimento de colônias, que indicou resistência à concentração CIM foi considerada como a primeira concentração de oxacilina que não apresentou crescimento (MANN \& MARKHMAN, 1998). Como controle foram utilizadas as cepas padrão de S. aureus sensível (ATCC 25923) e resistente à oxacilina (ATCC 29213) obtidas do Instituto Nacional de Controle de Qualidade/FIOCRUZ (KOHNER et al., 1999). Detecção do gene mecA pela técnica de reação em cadeia de polimerase (PCR): as enzimas proteinase $\mathrm{K}$ e lisozima foram utilizadas para a extração do DNA bacteriano e a amplificação do gene foi realizada utilizando-se os primers 5'AAAATC GAT GGTAAA GGT TGGC 3' e 5' AGT TCT GCA GTA CCG GAT TTG C 3'(COELHO et al., 2007). Análise estatística: para determinar o perfil de resistência fenotípica dos isolados bacterianos frente aos antibióticos testados, foi utilizado o software R2.4.1, (2006) e, para a determinação do perfil de resistência à oxacilina, foi realizada análise multivariada (HAIR et al., 2005). 


\section{RESULTADOS E DISCUSSÃO}

Dos 24 isolados provenientes de espécimes clínicas humanas, Staphylococcus cohnii subsp. cohnii foi a espécie mais prevalente e, dos 48 isolados provenientes de animais, $\boldsymbol{S}$. $x y l o s u s$ foi o microrganismo que apresentou maior freqüência. A tabela 1 apresenta o total de isolados de ECN provenientes de espécimes do conduto auditivo de cães, de mastite bovina e espécimes humanas.

A tabela 2 apresenta os percentuais de resistência obtidos no teste de suscetibilidade aos diferentes antibióticos provenientes de amostras humanas e animais. Os resultados apontam para um elevado percentual de resistência à penicilina $\mathrm{e}$ ampicilina em todos os isolados, apresentando similaridades aos resultados encontrados na literatura, como nos estudos de TENSSAY (2000) que analisou $432 \mathrm{ECN}$ e encontrou $95 \%$ de resistência à penicilina $\mathrm{e}$ BARELLI et al. (1999), que encontraram 88,6\% de resistência à penicilina em 42 isolados de $S$. epidermidis. Os isolados provenientes de humanos e do conduto auditivo de cães apresentaram $12,5 \%$ e $15,6 \%$ de resistência à gentamicina, respectivamente. Não foi detectada resistência a este antibiótico nos isolados de mastites testados. Segundo FARIAS (2002), os aminoglicosídeos têm se mostrado efetivos contra infecções por estafilococos, sendo, portanto, apontados como fármacos de eleição no tratamento destas infecções. Estes resultados corroboram com os achados de LILENBAUM et al. (2000), que, em um total de 44 isolados de Staphylococcus spp. observaram $15,9 \%$ de resistência à gentamicina.

As espécies isoladas de humanos e de cães apresentaram $16,7 \%$ e $15,6 \%$ de resistência à vancomicina, respectivamente. Percentuais considerados elevados se comparados ao trabalho desenvolvido por TAHNKIWALE et al. (2002), no qual não foi detectada resistência à vancomicina frente a 230 isolados de Staphylococcus spp. Os isolados bovinos não apresentaram resistência à vancomicina, à semelhança do que ocorrera com a gentamicina. A resistência à vancomicina entre os ECN foi relatada pela primeira vez há 20 anos (TUAZON \& MILLER, 1983) e, atualmente, isolados de ECN têm demonstrado um aumento na resistência a este antibiótico. Segundo DOMARACKI et al., 1998, é possível que o aumento dessa resistência, ao passar dos anos, esteja associado à constante exposição à vancomicina e à sucessiva pressão seletiva, ocasionando na transferência do gene de resistência entre as cepas.

A associação beta-lactâmico mais inibidor de beta-lactamase foi o antibiótico que apresentou menor percentual de resistência nos isolados de cães, representando $12,5 \%$. Nos isolados humanos, a resistência foi de $4,2 \%$ e nenhum isolado de mastite bovina apresentou resistência. MONROY et al. (2003) avaliaram 73 isolados de estafilococos frente a diferentes antibióticos, em que a associação ampicilina+sulbactam se mostrou bastante eficaz e HIRANO \& BAYER (1991) sugeriram que ampicilina+sulbactam é uma opção terapêutica para as infecções causadas por cepas produtoras de betalactamase e multirresistentes. Os baixos valores de resistência encontrados, possivelmente, estão relacionados ao custo e ao uso ainda restrito deste tipo de antibiótico nas clínicas veterinária e humana (RUSSEL \& CHOPRA, 1996).

Os isolados do conduto auditivo de cães, mastite bovina e isolados nosocomiais apresentaram $50 \%, 37,5 \%$ e $54,2 \%$ de resistência à cefoxitina, respectivamente. CAUWELIER et al. (2004) avaliaram a resistência de 155 isolados de ECN a este antibiótico, sendo $60 \%$ dos isolados resistentes, confirmando o trabalho desenvolvido por PALAZZO \& DARINI (2006) que obtiveram $49,66 \%$ de resistência dos 151

Tabela 1 - Distribuição dos espécimes de Staphylococcus spp. coagulase negativos (ECN) isolados obtidos de cães, bovinos e humanos.

\begin{tabular}{|c|c|c|c|}
\hline \multirow{2}{*}{ Espécies de ECN } & \multirow[b]{2}{*}{ Cães } & \multirow[b]{2}{*}{ Bovinos } & \multirow[b]{2}{*}{ Humanos } \\
\hline & & & \\
\hline S. cohnii subsp. cohnii & 03 & - & 06 \\
\hline S. haemolyticus & 02 & 01 & 05 \\
\hline S. cohnii subsp. urealyticus & 04 & 04 & 03 \\
\hline S. xylosus & 09 & 05 & 02 \\
\hline S. simulans & 03 & - & 02 \\
\hline S. hominis & 06 & 02 & 02 \\
\hline S. capitis subsp. capitis & - & - & 02 \\
\hline S. epidermidis & 02 & 02 & 01 \\
\hline S. capitis subsp. urealyticus & 03 & 02 & 01 \\
\hline Total & 32 & 16 & 24 \\
\hline
\end{tabular}

Ciência Rural, v.38, n.5, ago, 2008. 
Tabela 2 - Percentual de resistência dos isolados de Staphylococcus spp. coagulase-negativos de diferentes origens.

\begin{tabular}{|c|c|c|c|}
\hline Antibióticos & $\begin{array}{l}\text { Cães } \\
(n=32)\end{array}$ & $\begin{array}{l}\text { Bovino } \\
(n=16)\end{array}$ & $\begin{array}{c}\text { Humanos } \\
(n=24)\end{array}$ \\
\hline Ampicilina & 87,5 & 18,8 & 91,7 \\
\hline Penicilina & 87,5 & 18,8 & 91,7 \\
\hline Gentamicina & 15,6 & 00 & 12,5 \\
\hline Vancomicina & 15,6 & 00 & 16,7 \\
\hline Oxacilina & 56,2 & 00 & 79,2 \\
\hline Amp + sulb & 12,5 & 00 & 4,2 \\
\hline Cefoxitina & 50 & 37,5 & 54,2 \\
\hline
\end{tabular}

isolados de ECN avaliados. A cefoxitina apresenta alta afinidade com a PBP2, a PBP4 e resistência à oxacilina, sendo indutora na expressão do gene mecA e apresentando grande especificidade (CAUWELIER et al., 2004).

Os isolados de espécimes humanos apresentaram 79,2\% de resistência à oxacilina. Nos isolados do conduto auditivo, a resistência foi de $56,2 \%$ e os isolados de mastite bovina não apresentaram resistência ao fármaco. JOHN et al. (2002) analisaram 658 ECN e encontraram índices de resistência à oxacilina para $\boldsymbol{S}$. epidermidis e $\boldsymbol{S}$. haemolyticus igual a $62 \%$ e $82 \%$, respectivamente. No trabalho desenvolvido por TERASAWA (2006), os índices de resistência à oxacilina também foram elevados, sendo de $83,9 \%$ em 118 isolados de S. epidermidis e 97,92\% em 48 isolados de $\boldsymbol{S}$. haemolyticus. Segundo JACOBY \& ARCHER (1991), a transferência horizontal do gene de resistência mecA em clones de Staphylococcus spp. coagulasenegativos possivelmente ocasionou a disseminação mundial de clones oxacilina-resistentes.

No presente trabalho, os isolados resistentes à oxacilina demonstraram $100 \%$ de resistência à penicilina e ampicilina e índice de resistência inferior a $19 \%$ aos demais fármacos, corroborando os resultados de FERREIRA et al. (2003), que, ao avaliar isolados de $\mathrm{ECN}$, encontraram baixos níveis de resistência à gentamicina, vancomicina, clindamicina, teicoplanina e tetraciclina, com exceção apenas à penicilina.

A detecção da resistência à oxacilina pela utilização de métodos fenotípicos apresenta problemas devido à expressão heterogênea do gene mecA (CAUWELIER et al., 2004). Por isso, metodologias têm sido desenvolvidas para aumentar a detecção de isolados verdadeiramente resistentes à oxacilina. No presente trabalho, os isolados de ECN demonstraram diferentes comportamentos fenotípicos de resistência nos testes utilizados em que possivelmente uma população apresentava tanto organismos suscetíveis quanto organismos resistentes. Porém, o reduzido número de isolados mecA positivos (Figura 1) encontrados, correspondendo a apenas $5,55 \%$ do total de isolados avaliados, não permitiu avaliar a sensibilidade e a especificidade destes testes, assim como, não foi possível estabelecer o grau de correlação entre a cefoxitina e a oxacilina como método de predição do gene por meio da análise multivariada (Fatorial Q). Todos os isolados mecA positivos foram provenientes de amostras animais, sendo três $\boldsymbol{S}$. xylosus e uma Staphylocococus epidermidis. Relatos sobre a presença do gene mecA em determinadas espécies de ECN são escassos (FERREIRA et al., 2003). Estudos como os de BANNERMAN (2003) e FERREIRA et al., (2003) reportam alta prevalência de isolados de $\boldsymbol{S}$. epidermidis e $\boldsymbol{S}$. haemolyticus mecA positivos associados à infecção hospitalar provocada por contaminação de fômites. Estas espécies são altamente relatadas em amostras humanas, porém, no presente estudo, apresentaram baixa freqüência, possivelmente, devido aos sítios de coleta das amostras. BROWN (2001) relata que isolados resistentes à oxacilina em diferentes testes fenotípicos podem não apresentar o gene $m e c A$, sendo que este fato pode ser explicado pelo fenótipo de hiperprodução de beta-lactamases.

\section{CONCLUSÃO}

Os isolados clínicos de Staphylococcus spp. coagulase-negativos provenientes de amostras coletadas de animais e humanos apresentaram elevada resistência à penicilina e à ampicilina, sendo a associação beta-lactâmico mais inibidor de betalactamase o antibiótico que apresentou menor percentual de resistência nos isolados do conduto auditivo, possivelmente pelo uso restrito na terapêutica veterinária. Não houve correlação entre a cefoxitina e a oxacilina como método de predição do gene mecA 
devido ao reduzido número de isolados mecA positivos. A heterorresistência à oxacilina em ECN foi demonstrada frente às diferenças de características de crescimento nos testes utilizados.

\section{AGRADECIMENTOS}

Os pesquisadores agradecem ao Curso de Pósgraduação em Microbiologia Veterinária, ao Laboratório de Biologia Molecular do Curso de Pós-graduação em Ciências Veterinárias, ao Instituto Fernandes Figueira/FIOCRUZ, pelos isolados humanos, e à Coordenação de Aperfeiçoamento de Pessoal de Nível Superior (CAPES), pelo apoio financeiro concedido.

\section{REFERÊNCIAS}

BANNERMAN, T.M. Staphylococcus, Micrococcus and other catalase-positive cocci that grow aerobically. In: MURRAY, P.R. (Ed.). Manual of clinical microbiology. 8.ed. Washington, DC: ASM, 2003. V.1, p.384-404.

BARELLI, C. et al. Evaluation of the antimicrobial susceptibilities of coagulase-negative staphylococci by E test. Revista Latinoamericana Microbiologia, v.41, n.2, p.6772, 1999.

BROWN, D.F.J. Detection of methicillin/oxacillin resistance in staphylococci. Journal Antimicrobial Chemotherapy, v.48, p.65-70, 2001.

CAUWELIER, B. et al. Evaluation of a disk diffusion method with cefoxitin $(30 \mu \mathrm{g})$ for detection of methicillin-resistant Staphylococcus aureus. European Journal Microbiology Infectious Disease, v.23, p.389-392, 2004.

CLINICAL AND LABORATORY STANDARDS INSTITUTE. Performance standards for antimicrobial disk susceptibility tests. (Approved standards. CLSI document M2-A3). Wayne, Pa: Clinical and Laboratory Standards Institute, 2005. p.M100-S15.

COELHO, S.M.O. et al. Mapeamento do perfil de resistência e detecção do gene mecA em Staphylococcus aureus e Staphylococcus intermedius oxacilina-resistentes isolados de espécies humanas e animais. Ciência Rural, v.37, n.1, p.195200, 2007.

DOMARACKI, B.E. et al. Increased oxacillin activity associated with glycopeptides in coagulase-negative staphylococci. European Journal Clinical Microbiology Infectious Disease, v.17, p.143-150, 1998.

FARIAS, M.F. Terapêutica otológica. In: FARIAS, M.F et al. Manual de terapêutica veterinária. 2.ed. São Paulo: Roca, 2002. p.198-204.

FERREIRA, R.B.R. et al. Coagulase-negative staphylococci: comparison of phenotypic and genotypic oxacillin susceptibility tests and evaluation of the Agar screen test by using different concentrations of oxacillin. Journal of Clinical Microbiology, v.41, n.8, p.3609-3614, 2003.

GENTILINI, E. et al. Antimicrobial susceptibility of coagulasenegative staphylococci isolated from bovine mastitis in Argentina. American Dairy Science, v.85, p.1913-1917, 2002 .
HAIR, J.F. et al. Análise multivariada de dados. 5.ed. Porto Alegre: Bookman, 2005. p.595.

HIRANO, L..; BAYER, A.S. b-Lactam-b-lactamase inhibitor combinations are active in experimental endocarditis caused by b-lactamase-producing oxacillin-resistant staphylococci. Antimicrobial Agents and Chemotherapy, v.35, p.685$690,1991$.

JACOBY, G.A.; ARCHER, G.L. New mechanisms of bacterial resistance to antimicrobial agents. New England Journal Medicine, v.324, n.9, p.601-612, 1991.

JOHN, M.A. et al. In vitro activity of quinupristin/dalfopristin, linezolid, telitromycin and comparator antimicrobial agents against 13 species of coagulase-negative staphylococci. Journal of Antimicrobial Chemotherapy, v.50, p.933-938, 2002.

KONEMAN, E.W. et al. Diagnóstico microbiológico. 5.ed. Rio de Janeiro: MEDS, 2001. p.551-588.

KOHNER, J.P. et al. Comparison of susceptibility testing methods with mecA Gene analysis for determining oxacilin resistance in clinical isolates of Staphylococcus aureus and coagulase negative staphylococcus spp. Journal of Clinical Microbiology, v.37, n.9, p.2952-2961, 1999.

LILENBAUM, W. et al. Antimicrobial susceptibility of Staphylococci isolated from otitis externa in dogs. Letters Apllied Micology, v.31, p.42-45, 2000.

MANN, C.; MARKHAM, J.L.A. New method for determining the minimum inhibitory concentration of essential oils. Journal of Applied Microbiology, v.84, p.538-544, 1998.

MONROY, P.E. et al. Comparación de la efectividad de antibióticos ß-lactámicos en cepas de Staphylococcus aureus. Revista del Hospital General Dr. Manuel Gea González, v.6, n.1, p.7-12, 2003.

PALAZZO, I.C.; DARINI, A.L. Evaluation of methods for detecting oxacillin resistance in coagulase-negative staphylococci including cefoxitin disc difusion. Microbiology Letters, v.257, p.299-305, 2006.

RUSSEL, A.D.; CHOPRA, I. Understanding antibacterial action and resistance. 2.ed. United Kingdom: Ellis Horwood Chichester, 1996. p.226-237.

TENSSAY, Z.W. Staphylococci: frequency of isolation and antibiotic susceptibility pattern in Jimma Hospital, south-west Ethiopia. Journal Ethiopia Medicine, v.38, n.3, p.175184,2000 .

TAHNKIWALE, S.S. et al. Methicillin resistance among isolates of Staphylococcus aureus: antibiotic sensitivity pattern \& phage typing. Archives of Internacional Medicine, v.56, n.7, p.330, 2002 .

TERASAWA, L.B. Caracterização da resistência à oxacilina em estafilococos coagulase-negativos isolados no hospital de clínicas de Curitiba - Paraná. 2006. 132 f. Dissertação (Mestrado em Microbiologia, Parasitologia e Patologia) - Universidade Federal do Paraná.

TUAZON, C.U.; MILLER, H. Clinical and microbiologic aspects of serious infections caused by Staphylococcus epidermidis. Scand. Journal Infectious Disease, v.15, p.347$360,1983$. 